\title{
The NCEP ATP III criteria may overestimate the diagnosis of metabolic syndrome in obese and overweight adolescents
}

\author{
Hasan Sav(1), Umut Mousa (1), Osman Koseoglulari (1), Ruveyde Bundak(2) \\ 1: B Nalbantoglu Hospital Department of Endocrinology and Metabolism, Nicosia, Cyprus \\ 2: Istanbul University Hospital, Department of Pediatrics, Istanbul, Turkey
}

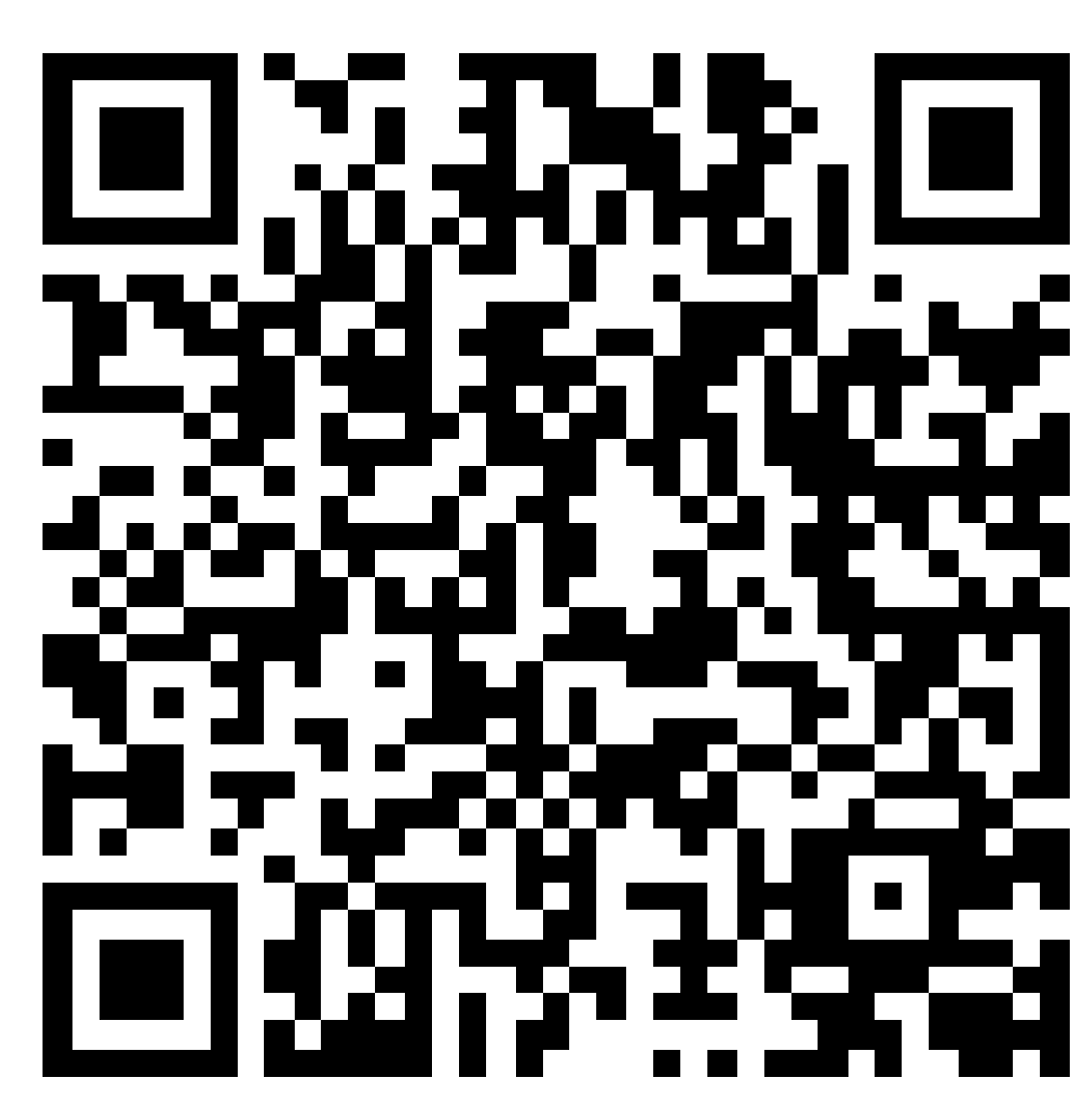

\section{OBJECTIVES}

The optimum definition of the metabolic syndrome (MetS) is a matter of debate in children. In this study we aimed to compare the previously reported international definitions of MetS according to the National Cholesterol Education Program, Adult Treatment Panel III (NCEP, ATP III) and International Diabetes Federation (IDF) in a cohort of obese and overweight children and adolescents.

\section{METHODS}

We included 320 subjects in our study. We measured the subjects' plasma glucose, high density lipoprotein cholesterol, triglycerides in a fasting serum sample. We measured the height to the nearest centimeter and weight to the nearest kilogram. The subjects' blood pressure was measured via a sphygmomanometer. The body mass index was calculated by dividing the weight in kilograms to the height in centimeters squared. The waist circumference was measured by a tape over the umbilicus to the nearest centimeter when the subject was standing in upright position.

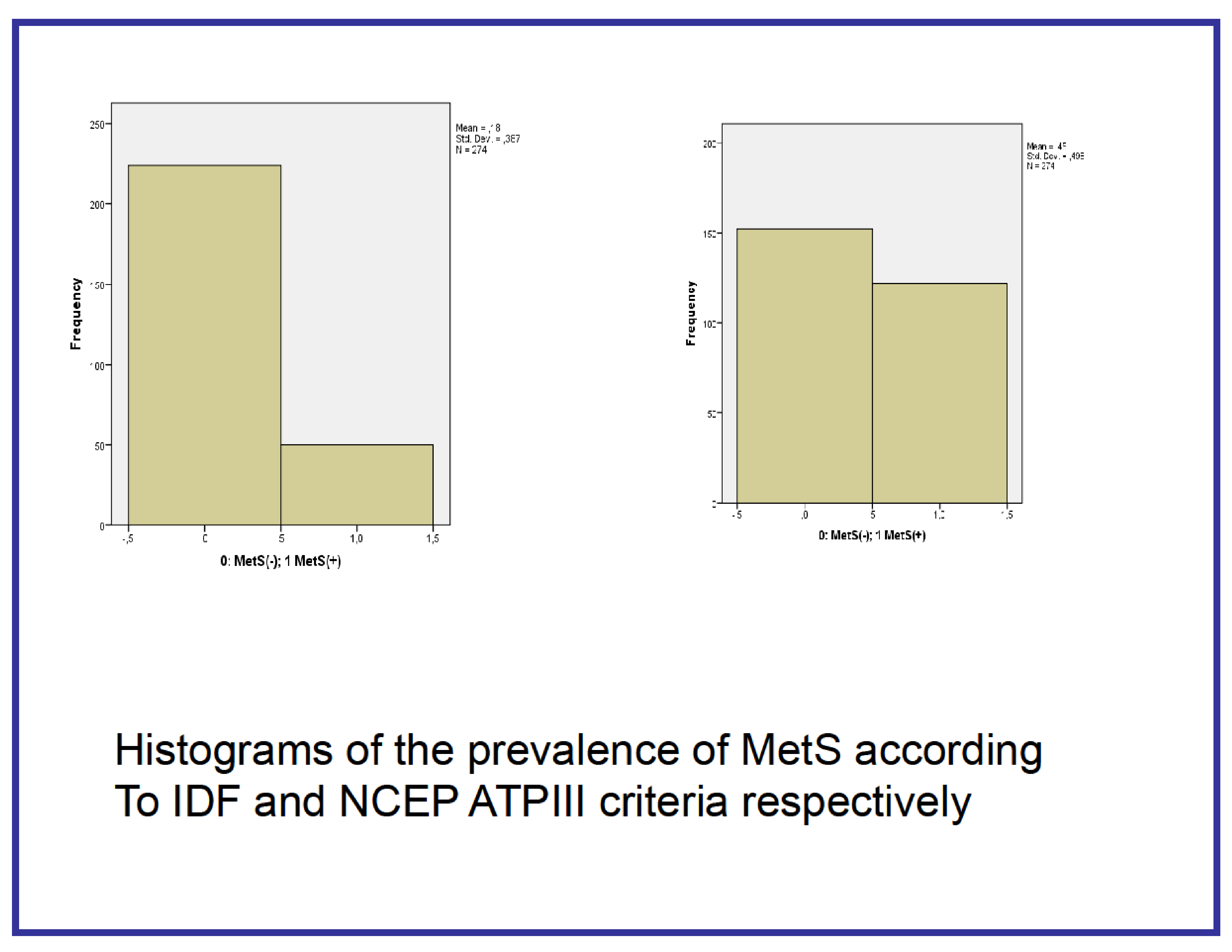

\begin{tabular}{|c|}
\hline RESULTS \\
\hline $\begin{array}{l}\text { The age ranged between } 9.33 \text { and } 16 \text { years in the study group. } \\
\text { The mean age of the study group was } 13.74 \text { years. According to } \\
\text { standard percentiles } 46 \text { were overweight and } 274 \text { were obese. } \\
156(48.8 \%) \text { of the study group were female and } 164(52.2 \%) \\
\text { were male. Out of the } 46 \text { overweight subjects } 17.4 \% \text { and } 28.9 \% \\
\text { of subjects were diagnosed as MetS according to the IDF } \\
\text { criteria and NCEP ATPIII criteria respectively. Similar in the } \\
\text { obese group of } 274 \text { subjects } 18.2 \% \text { and } 44.5 \% \text { were diagnosed } \\
\text { as MetS according to the IDF criteria and NCEP ATPIII criteria } \\
\text { respectively. The comparisons were statistically significant } \\
(\mathrm{p}<0.05) \text {. }\end{array}$ \\
\hline
\end{tabular}

\section{CONCLUSIONS}

Similar to previous studies the NCEP ATPIII criteria may overestimate the prevalence of MetS in overweight and obese adolescents. 